\title{
Review
}

\section{Eating disturbances in the elderly: A geriatric-psychiatric perspective}

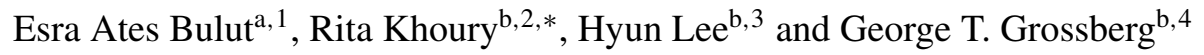 \\ ${ }^{a}$ Department of Geriatric Medicine, Dokuz Eylul University, Faculty of Medicine, Izmir, Turkey \\ ${ }^{\mathrm{b}}$ Department of Psychiatry and Behavioral Neuroscience, Saint Louis University School of Medicine, \\ Saint Louis, MO, USA
}

\begin{abstract}
The prevalence of malnutrition among older adults is increasing, leading to poor health outcomes and increased mortality. This review sheds light on the different etiologies of eating disturbances in the elderly and discusses assessment tools and treatment strategies. Older adults are found to be more prone to nutritional deficiencies and weight loss due to age related physiological and psychosocial changes, in addition to pathological medical and psychiatric disorders. The short form of the Mini Nutritional Assessment is considered the most commonly used screening tool in older persons. Individuals identified as malnourished or at high risk of malnutrition would benefit from comprehensive treatment plans according to the underlying etiology. Those involve environmental changes, oral nutritional supplements and ultimately pharmacotherapy.
\end{abstract}

Keywords: Malnutrition, anorexia, cachexia, appetite, involuntary weight loss, older population

\section{Introduction}

Nutrition is one of the most important determinants of physical and mental health, and plays a key role in successful aging. Given the increase in life expectancy, older adults have become a rapidly growing portion of the world's population. In the United States, the prevalence of adults aged 65 years and above increased from 36.6 million in 2005 to 47.8 million in 2015 (a 30\% increase) and is predicted to more than double by 2060, reaching around 98 million [1]. With population aging, eating disturbances and malnutrition have increasingly become an important health issue to address. Malnutrition can

\footnotetext{
${ }^{1}$ ORCID ID: 0000-0002-1124-9720

${ }^{2}$ ORCID ID: 0000-0003-2481-6816

${ }^{3}$ ORCID ID: 0000-0003-0954-9174

${ }^{4}$ ORCID ID: 0000-0002-1493-3931

*Corresponding author: Rita Khoury, MD, Department of Psychiatry and Behavioral Neuroscience, Saint Louis University School of Medicine, 1438 S Grand Blvd, St. Louis, MO 63104, USA. Tel.: +1 314977 4825; E-mail: rita.khoury @ health.slu.edu.
}

be defined as "a state resulting from lack of intake or uptake of nutrition that leads to altered body composition (decreased fat free mass) and body cell mass, leading to diminished physical and mental function and impaired clinical outcome from disease" [2].

Although there have been no uniformly established diagnostic criteria for malnutrition, clinicians and researchers have relied on anthropometric measures, biochemical markers and specific screening tools to identify patients suffering from malnutrition [3]. Its prevalence is reported to range between $5-10 \%$ among community-dwelling older adults, compared to $30-61 \%$ among hospitalized elderly patients, and $12-85 \%$ among residents of long-term and subacute care facilities [4-6]. Despite the availability of various nutrition assessment tools, less than $40 \%$ of malnutrition cases are identified upon hospital admission [7]. The etiology of malnutrition appears to be complex and multifactorial. It involves physiological, psychological, social and economic factors, often summarized using the acronym the "nine d's" comprising dementia, dysgeusia, dysphagia, diarrhea, 
depression, disease (acute, chronic), poor dentition, dysfunction (functional disability), and drugs [8]. Large longitudinal studies such as the National Health and Nutrition Examination Surveys (NHANES) [9] and the Baltimore Longitudinal Study [10] have shown a critical decline of weight and energy intake with aging, leading to "anorexia of aging" as the most common eating disturbance in the elderly. Anorexia of aging can thus be physiological, due to age-related modifications in the digestive system, appetite, body composition and energy requirement/expenditure. However, it can become pathological, when comorbid medical and psychiatric diseases co-occur along with those physiological changes. Furthermore, social, economic and cultural factors may affect older adults' eating patterns [11].

Regardless of the causes, malnutrition in the elderly has significant medical and socio-economic impact on patients and families: unintentional weight loss, a major manifestation of malnutrition, has been shown to be related to frailty, sarcopenia, dementia, recurrent falls and worse health outcomes [12]. Older hospitalized patients with malnutrition are reported to have longer lengths of stays, higher healthcare costs, and increased mortality [13]. Adequate nutritional support is found to be essential to regulate the older adult's immune system, prevent infections, and improve the musculo-skeletal system, functional status and neurocognitive functions [14].

A careful nutritional evaluation is hence one of the main components of a comprehensive geriatric assessment to implement necessary treatment plans to achieve successful aging in the elderly.

The aim of this paper is to review the multiple etiologies of eating disturbances in the elderly and discuss the most up-to-date assessment tools and management strategies for this under-recognized geriatric syndrome. For this purpose, we reviewed the PUBMED database for relevant articles published up to July 2018 using the following keywords: 'malnutrition', 'eating disorders', 'appetite', 'body weight and composition', 'nutrition', "elderly”, "older adult", "geriatric" and "anorexia".

\section{Etiologies of eating disturbances in the elderly}

\subsection{Age-related physiological changes}

\section{Gastrointestinal}

Aging gives rise to a disruption in gustatory and olfactory sensations leading to impairment of the cephalic phase of digestion (phase I) that regulates appetite and food ingestion via sensory outputs such as sight and smell, before or while the food is being eaten [15]. Additionally, poor dentition/tooth loss, commonly seen in the elderly with dry mouth, may also result in chewing and swallowing difficulties and impaired digestion [16]. Older adults tend to have consequently longer duration gastro-esophageal reflux due to reduced peristalsis and impaired lower esophageal sphincter contraction [17]. Moreover, changes of the myenteric plexus with aging leads to impaired gastric emptying which causes distention and earlier satiety [18]. Also, older adults may have reduced gastric acid and pepsin secretion, commonly related to Helicobacter pylori infection. Higher prevalence of hypochlorhydria and achlorhydria are seen which may compromise oral drug bioavailability and absorption of food, vitamins (vitamin B12, vitamin D), and minerals (calcium, iron) [19]. Furthermore, decrease in pancreatic enzymes, bile acids and liver enzymes' activity notably the cytochrome P450 system, contribute to impairment of absorption, digestion and enhance drug-drug interaction and the risk of adverse events [20].

\section{Neuroendocrine}

Central and peripheral hormones play a role in the regulation of appetite. Central hormones include opioids, neuropeptide Y (NPY), galanin and orexins; and peripheral hormones are cholecystokinin (CCK), ghrelin, glucagon like peptide-1 (GLP-1), peptide YY (PYY), leptin, adiponectin, insulin, glucagon, amylin, corticotrophin-releasing factor (CRF), and serotonin [21]. Satiety seems to be modulated by a reduction of neurotransmitters that induce appetite also known as orexigenic (e.g. ghrelin, NPY, opioids) and an increase in those that decrease appetite (anorexics) such as CCK, GLP-1, leptin and CRF. $\mathrm{CCK}$, released from the intestine after food ingestion, is reported to be elevated in older adults, causing greater satiety [22]. In a similar pattern, GLP-1 another potent anorexic, involved in stimulating insulin secretion and delaying gastric emptying, was shown to have increased physiological levels in elderly [23]. Leptin is produced mainly in adipose cells and regulates energy intake according to fat stores. Older adults tend to have high levels of leptin because of increased adiposity, increasing satiety [24]. On the other hand, ghrelin is an orexigenic peptide produced in the gastric fundus that activates nitric oxide (NO) in the hypothalamus and stimulates growth hormone $(\mathrm{GH})$ secretion. $\mathrm{NO}$ and $\mathrm{GH}$ 
are also anabolic hormones that induce food intake. Studies have shown a small decrease in ghrelin levels in older adults compared to younger persons, which may contribute to their anorexia [25].

Appetite is further regulated in the central nervous system via the hypothalamus, particularly through the ventromedial hypothalamic nucleus (satiety center), the lateral hypothalamic area (hunger center) and the arcuate nucleus [22]. These 3 areas are connected to the amygdala and the nucleus tractus solitarius where the integration of peripheral satiety signals with hypothalamic and supra-hypothalamic information takes place. Aging has been shown to affect neurotransmitter levels in these centers, notably the endogenous opioids $\beta$-endorphin, enkephalin, and dynorphin involved in stimulating food ingestion through kappa receptors [26]. Decreased dynorphin stimulation with age causes a decline in opioid receptor function and reduced NPY responsiveness contributing to anorexia in the older population [27, 28].

\section{Body composition}

Changes in body composition, energy expenditure and functional status of organs that occur with aging influence the energy homeostasis and nutritional status of older adults. Physiological changes in body composition may begin after the fourth decade and involve muscle loss and increased fat: skeletal muscle loss rate is reported to be $8 \%$ per decade between the age of 50 and 70 years, and $10-15 \%$ per decade after 70 years $[29,30]$. Predominant visceral rather than subcutaneous fat distribution may lead to insulin resistance [31], which increases muscle catabolism even further [32]. In addition, sex steroid levels tend to decline with aging. Increased sex hormone binding globulin also leads to lower bioavailable testosterone, which is an anabolic hormone that plays a key role in muscle mass and strength [33]. All these changes contribute to sarcopenia, which is characterized by loss of muscle strength, mass and functionality. In addition to sarcopenia, decreased fat free mass and high metabolic organ activity (heart, brain, kidney) result in reduced resting energy expenditure (REE) [34]. Furthermore, physical inactivity often seen with old age is closely related to sarcopenia and reduced REE. Decreased appetite may thus be one of the adaptive mechanisms to regulate reduced REE in the elderly.

\section{Cytokines}

Although cytokines are generally produced in response to a significant stress like a malignancy, aging itself may be a form of stress that may alter cytokine production [22]. Aging individuals usually have increased cortisol and catecholamine levels inducing the release of pro-inflammatory cytokines such as interleukin (IL)-6 and tumor necrosis factor (TNF)- $\alpha$, the levels of which have been shown to inversely correlate with the degree of functional ability in the elderly. Increased TNF- $\alpha$ levels have been shown to correlate with increasing levels of the anorexic circulating leptin, and to induce muscle breakdown and reduce the sensitivity of skeletal muscle cells to anabolic stimuli [35]. Increased IL-6 levels contribute to anorexia through an activation of the hepatic acute phase response, and the hypothalamic-pituitary-adrenal axis, leading to bone and muscle loss [36]. Pro-inflammatory cytokines create an anorexigenic, catabolic, hypermetabolic state [35]. Table 1 summarizes the anorexigenic effects of major cytokines including IL- $1 \beta$ and 6 , TNF- $\alpha$, INF- $\gamma$ and leptin [36].

\subsection{Social, economic and cultural factors}

From a social perspective, adhering to a healthy and balanced pattern of eating may be affected by several factors that may be physical (food availability), economical (affordability), socio-cultural

Table 1

Role of major cytokines in anorexia

\begin{tabular}{ll}
\hline Cytokines & Effects \\
\hline Interleukin-1 $\beta$ & Pro-inflammatory, induces fever, acute phase response and activates \\
& Nuclear Factor kappa (NF-K), regulates serotonin and central \\
& melanocortin system \\
Tumor necrosis factor (TNF)- $\alpha$ & Pro-inflammatory, increases leptin, causes oxidative stress and \\
& muscle breakdown, blocks $\beta$ endorphin \\
Interleukin-6 & Both pro and anti-inflammatory, activates NF-K, increases leptin \\
Interferon- $\gamma$ & Pro-inflammatory, amplifies the effect of TNF $\alpha$ and IL-1 \\
Leptin & Suppresses appetite, causes anorexia \\
\hline
\end{tabular}

Adapted from Morley JE, et al. Cytokine-related aging process. The journals of gerontology Series A [36]. 
(norms and values) and/or political (rules and laws) [37]. Community-dwelling older adults are at higher risk of malnourishment because of difficulty relative to accessing food/ transportation to grocery stores, or in paying for food due to limited incomes, much of which may be spent on healthcare expenses. Food attitudes, cultural preferences and religious beliefs are also determinants of food choices [38]. In addition, low levels of education and common incorrect beliefs regarding the need for dietary restrictions may lead to poor food choices [39]. Furthermore, older adults who live alone, especially males, are reported to have a significantly increased risk of poor nutrition, highlighting the importance of social isolation as a risk factor for malnourishment [40]. Moreover, older adults are more prone to being victims of psychological and/or physical abuse, financial exploitation, and caregiver neglect putting them at additional risk of malnutrition [41].

Although nursing home residents are the most cognitively impaired and frail patients, which puts them theoretically at a higher risk of malnourishment, being in an institutionalized setting, rather than being socially isolated, may enhance their chances of getting better nutrition via regularly scheduled meals during the day [42].

\subsection{Pathological medical conditions and polypharmacy}

Anorexia in the elderly can result from systemic diseases such as chronic heart failure, chronic kidney disease, chronic obstructive pulmonary disease, rheumatologic diseases, cancer, and acute illnesses. The common denominator for these conditions is systemic inflammation and a hypercatabolic state, ultimately leading to cachexia [35]. Pro-inflammatory cytokines (IL-6, IL-1, TNF- $\alpha$ ) induce serotonergic neurons and the melanocortin system in the hypothalamus leading to reduced appetite. Additionally, they inhibit transcription of the myosin heavy chain and induce its proteolysis via the ubiquitin-proteasome mechanism leading to cachexia. Furthermore, stress and chronic inflammation activate the adrenocortical system and catecholamines secretion, enhancing basal metabolic rate and production of reactive oxygen species, leading to protein degradation. Therefore, cachexia is a serious "wasting" disorder that is not a consequence of starvation or age-related muscle loss and does not typically respond to increased caloric intake [43]. Moreover, other diseases such as malabsorption syndromes, hypermetabolic states such as hyperthyroidism may also lead to anorexia in older adults [39].

In a prospective observational study involving 1419 older adults aged 65 years and above, Bosch et al. found $2 / 3$ of unintentional weight loss cases were attributed to malignant and non-malignant organic disorders. $50 \%$ of non-malignant organic disorders were digestive disorders such as gastric and duodenal ulcer, colitis, in addition to swallowing and dental problems [44]. Patients with malignancies were predominantly older men, with more pronounced weight loss. Therefore, it is important to differentiate malignant disorders in patients with red flag signs [44].

Dysphagia is nowadays considered a new geriatric syndrome leading to malnutrition, that needs to be screened for in older adults with neurological/neurodegenerative diseases such as cerebrovascular accidents, Parkinson's disease and major neurocognitive disorders or dementias [45, 46]. Parkinson's disease gives rise to alterations in the dopaminergic, serotonergic, noradrenergic and cholinergic neurotransmitter systems. Not only dysphagia, but also delayed gastric emptying, constipation, disturbed hand-mouth coordination and comorbid mood disorders may have a serious impact on nutritional status in these patients [47]. Medications such as NSAIDS, bisphosphonates and potassium supplements may also cause dysphagia [48].

Additionally, obesity, poor salivation and concomitant use of medications that affect esophageal motility such as anticholinergics, calcium antagonists, benzodiazepines and theophylline, autonomic neuropathy which is common in neurodegenerative diseases and diabetes mellitus are risk factors for developing gastroesophageal reflux (GERD). GERD should be especially considered in patients who present with loss of appetite and weight due to dyspepsia [49]. Atrophic changes in the gastrum (atrophic gastritis) may also result in micronutrient deficiency and malabsorption [50]. Data relative to gastric motility changes with aging is conflicting, but delayed gastric emptying is commonly seen, causing early satiety and reduced appetite [51, 52].

Moreover, reduction of myenteric neurons, neuropathy, metabolic derangements (e.g hypothyroidism, hypercalcemia), drugs (e.g. anticholinergics, antihypertensives, opioids, antacids), decreased rectal compliance and sensation, decreased fluid intake and physical activity, all contribute to chronic 
Table 2

Commonly prescribed medications affecting taste and appetite

\begin{tabular}{ll}
\hline Medication Class & Side Effects \\
\hline $\begin{array}{l}\text { Antibiotics } \\
\quad \text { (macrolides, metronidazole, fluoroquinolones) }\end{array}$ & Dysgeusia \\
Anti-epileptics (carbamazepine, phenytoin) & \\
Mood stabilizer (lithium) & Dysgeusia, nausea,vomiting \\
Antihypertensive medications (captopril, ramipril) & Dysgeusia \\
Anti-neoplastic drugs (5-fluorouracil, cisplatin) & Dysgeusia \\
Anti-parkinsonian drugs (levodopa, amantadine) & Dysgeusia, nausea, vomiting \\
Anticholinergics (antispasmodics, antimuscarinics, tricyclic & Dysgeusia, nausea,vomiting \\
$\quad$ anti-depressants) & Dysgeusia, dysphagia \\
Statins (atorvastatin, simvastatin) & \\
Muscle relaxants (baclofen) & Dysgeusia \\
Digoxin, hormone replacement therapy and phenytoin & Dysgeusia \\
Cholinesterase inhibitors (donepezil, rivastigmine) & Nausea,vomiting \\
\hline
\end{tabular}

Adapted from Syed Q, et al. The Impact of Aging and Medical Status on Dysgeusia, and Viswambharan V, et al. Orexigenic agents in geriatric clinical practice $[54,55]$.

constipation [52]. Elderly patients are also susceptible to fecal impaction and overflow diarrhea because of constipation.

Prescription of inappropriate medications is associated with adverse drug reactions such as altered taste, dry mouth, constipation and nausea, leading to reduced food intake [53]. Polypharmacy has also been shown to be a main risk factor for malnutrition in the elderly [53]. Several classes of medications (shown in Table 2) can adversely affect appetite and taste or may be associated with gastro-intestinal sideeffects such as nausea, vomiting and diarrhea $[54,55]$.

A recent meta-analysis has shown a 2-fold increased risk of weight loss in vulnerable patients diagnosed with dementia and taking cholinesterase inhibitors [56]. However, the rivastigmine patch formulation has been shown to be associated with less gastrointestinal side effects $[57,58]$. Sedatives and opiates may also affect the ability to eat independently without assistance in patients who develop severe sedation and impaired motor coordination [48].

\subsection{Psychiatric disorders}

\section{Eating Disorders (EDs)}

EDs are serious psychiatric disorders that are often overlooked in the elderly, as they typically occur in adolescents and young adults. Body-image related concerns are often neglected in older individuals, although they may constitute a core feature of pathological eating behaviors in this population [59]. Research has shown that the drive for thinness and body dissatisfaction may persist in the elderly, and they closely correlate with the fear of aging [60].

In a sample of community-dwelling Austrian women aged 60-70 years, the prevalence of EDs according to the DSM-IV criteria was 3.6\% [61]. Per the DSM-5 criteria, a similar prevalence $(3.25 \%)$ has been found in a sample of 342 Portuguese women aged 65-94 years old [62]. EDs in this population can be divided into young-onset disorders that have recurred or continued in later life and late-onset disorders that have emerged for the first time at an older age. Unfortunately, the definition of late-onset ED is not clear, due to the heterogeneity of studies and the reduced life-expectancy of these patients, but generally an onset after the age of 40 may be considered as late-onset [63].

EDs in the elderly are associated with increased morbidity and mortality: a study looking at published case reports up to 2008 has shown a $21 \%$ mortality rate associated with EDs occurring in older adults (mean age $=68.6$ years). The most frequent ED in this study's population was anorexia nervosa (AN), and surprisingly, late onset EDs were more common than recurrent early onset [64]. This finding contrasts with large community-based studies that reported binge eating disorder (BED) to be the most common ED in the elderly $[59,62,65]$.

Moreover, according to a study that compared prognosis of EDs among various age groups $(<18 \mathrm{vs}$ $18-39$ vs $>39$ years), older age was associated with higher likelihood of having a comorbid psychiatric diagnosis, greater psychological and physical constraints on disorder-specific measure of quality of life, and greater interpersonal problems. Older groups also 
experienced higher risk of death and poorer prognosis based on body mass index (BMI), eating habits, and number of ED criteria met at 1-11 year follow up [66].

EDs in older males are rare, estimated to be $0.02 \%$ in a survey of nearly 500,000 male veterans, mean age of $60.2(\mathrm{SD}=14.2)$ years [67]. Despite this drastic difference in epidemiology, a review of 16 cases of EDs in elderly men demonstrated that they share with women similar clinical presentation, precipitating events and degree of functional impairment [68]. Therefore, EDs need to be considered in the differential for unexplained weight changes in the elderly, regardless of the gender.

\section{1a. Anorexia Nervosa (AN)}

AN is characterized by restriction of energy intake leading to significant weight loss, fear of gaining weight, and disturbance of body image [69]. With a median age of onset of 18 , AN is seen as a disease of adolescents. However, older patients can also be affected by AN due to its chronic and relapsing disease course. A longitudinal study with 21 year follow up after $\mathrm{AN}$-associated hospitalizations showed that $21 \%$ of the patients had only partial recovery, and $10 \%$ continued to meet all diagnostic criteria [70]. AN may also emerge de novo in the elderly, a condition known as late-onset anorexia nervosa or "anorexia tardive". Anorexia tardive is believed to share important similarities with early-onset AN [71-73].

Body dissatisfaction is a crucial aspect of both the development and presentation of anorexia nervosa $[61,69]$. A survey of 106 women with AN showed no statistically significant difference in prevalence or degree of body dissatisfaction across all age groups (20-65 years old) [74]. Similarities between early and late-onset $\mathrm{AN}$ extend to the clinical presentation including age of menarche, duration of illness prior to presentation, weight at onset and upon presentation to a healthcare professional, and percentage of women partaking in high levels of physical activity or vomiting to lose weight [75].

Despite these similarities, important differences remain. For instance, depression is more common with anorexia tardive than with classic adolescent AN. Moreover, late-life stressors such as bereavement, domestic problems, and reduced social involvement are common precipitating factors for anorexia tardive [76, 77]. Another observational study showed that patients with anorexia tardive have greater disease severity, greater suicidality, more common misuse of substances for weight loss, more adequate emotional coping, and less body image distortion [78]. Additionally, prognosis is thought to be worse in anorexia tardive patients, often due to underdiagnosis of the disorder in older adults, leading to inadequate treatment $[75,78]$.

\section{1b. Bulimia Nervosa (BN)}

$\mathrm{BN}$ is characterized by binge eating (eating large amount of food with a sense of lack of control over eating) and compensatory behaviors, such as self-induced emesis, laxative or diuretic use, or compulsive exercise to prevent weight gain [69].

Much like AN, BN affects the older population by having late-onset or early onset forms with a chronic disease course. A 20-year follow-up of women with a mean age of $20 \pm 2$ years showed that $25 \%$ continued to suffer from BN [79]. An observational study of $919 \mathrm{BN}$ patients across various age groups (18-25 vs $26-39$ vs $>40$ years) showed that while the older population reported slightly less exercising and fewer binge eating episodes, BN presented very similarly across all age groups; there were no differences regarding demographics (race, gender, and marital status), fasting, self-induced vomiting, and laxative use [65].

\section{1c. Binge Eating Disorder (BED)}

BED is characterized by binge eating episodes accompanied by marked distress in the absence of compensatory behaviors to lose weight [69].

BED has a close association with other psychiatric conditions: about $37 \%$ of BED patients have comorbid specific phobias and, 29\% were shown to have a comorbid personality disorder with avoidant type being the most common $[80,81]$. Type II diabetes is another notable comorbid condition to be aware of in older adults with BED. A long-term study with 171 BED patients revealed a higher lifetime prevalence of diabetes in BED patients compared to the matched control group (34\% versus $4 \%$ ) [82]. Currently, there is no data investigating whether age is a modifier of comorbid conditions in BED patients. However, age appears to impact BED's presentation, by which older individuals (aged $>40$ years) have higher BMIs and report more medical problems, skip meals less often, exercise less often, and have less frequent binge eating episodes, when compared to their younger counterparts ( $<25$ years old). Interestingly, no significant difference in the degree of body dis- 
satisfaction was found between the two groups [65]. Much like other eating disorders, older BED patients have a higher mortality risk and a poorer prognosis compared to the youngest [66].

\section{Major Neurocognitive Disorders (MNCDs)}

MNCDs, also known as dementias, are defined by a significant decline in one or more domains of cognitive ability that interfere with daily activities in the absence of delirium or other attributable mental disorders [69]. Problematic eating behaviors are common behavioral symptoms in MNCDs, that can be assessed using the Neuropsychiatric Inventory (NPI) questionnaire [83]. They may be due to cognitive decline (forgetting to eat, failing to recognize food) and/or apraxia, in addition to insufficient caregiving (not having someone patiently feed an advanced MNCD patient) [84]. Furthermore, smell and taste dysfunction, dysphagia, chewing problems/poor dentition, functional impairment, and difficulties in social interaction may contribute to worsening of nutritional status [85]. Neurochemical imbalance involving serotonin and noradrenaline also impacts appetite in patients suffering from MNCDs [86]. The nature and frequency of the eating disturbance are dependent on the MNCD type and the underlying neuroanatomical circuits altered. While appetite loss is very common in Alzheimer's Disease (AD), increased appetite and alteration of food preference towards sweets is characteristic of frontotemporal dementia (FTD), thereby leading to significant weight gain [87, 88]. Also, depression and difficulty maintaining attention while eating are major contributors to weight loss in patients suffering from $\mathrm{AD}$ [89]. On the other hand, appetite changes seen in patients with the behavioral variant of frontotemporal dementia, have been partly related to hypothalamic degeneration, disruption of the connections between the hypothalamus and orbitofrontal cortex, and an increase in agouti-related peptide, a major hormone promoting food intake [90]. Patients with MNCD vascular type often suffer from dysphagia leading to increased eating difficulties and risk of aspiration pneumonia [91, 92]. Eating disturbances in Lewy body dementia are more prevalent than with AD. They may manifest as swallowing difficulties and decreased appetite sometimes attributed to distraction from visual hallucinations [93]. Moreover, eating disturbances are affected by the severity of the disease: in a prospective cohort study involving 220 AD patients, appetite loss was the most com- mon feature in the mild stages, compared to changes in food preference and eating habits in the moderate stages, and swallowing disturbances in the more severe stages [89].

\section{Depression}

Depression in late-life is a common psychiatric disorder affecting up to $35 \%$ of community-dwelling older adults [94]. The relationship between depression in older adults and appetite loss as a vegetative symptom is well-established; depression is one of the most common causes of weight loss in the elderly $[95,96]$. Diagnosing appetite loss due to a reversible cause such as depression in the elderly is crucial to prevent weight loss and nutritional deficiencies which may lead to increased frailty, failure to thrive, and increased mortality [96-98]. Furthermore, depression-related appetite disturbance may worsen the prognosis of comorbid diseases especially in cancer patients $[99,100]$. Appetite disturbance is not only a marker of worse outcomes but also a severity marker of cognitive deficits secondary to late-life depression [101]. Therefore, eating patterns of depressed elderly patients must be carefully assessed, and appetite disturbances promptly addressed.

\section{Assessment}

Given the serious impact of nutritional impairment on health outcomes in older adults, it is recommended to screen all geriatric patients for malnutrition both in inpatient and outpatient settings [102]. Unintentional weight loss is one of the most important predictors of malnutrition in older adults; a decline in weight of 5\% or more over three years is predictive of mortality in older adults [103]. Physicians commonly screen for the most common reversible causes of weight loss in the elderly by using the mnemonic Meals-on-Wheels shown in Table 3 [104].

Unfortunately, there is no globally accepted, gold standard tool, for diagnosis of malnutrition in the elderly. In 2012, the Academy of Nutrition and Dietetics and the American Society for Parenteral and Enteral Nutrition (ASPEN) suggested that the presence of 2 or more of the following 6 criteria is diagnostic of malnutrition: insufficient energy intake, weight loss, loss of muscle mass, loss of subcutaneous fat, localized or generalized fluid accumulation that may mask weight loss, and diminished functional status as measured by handgrip strength [105]. 
Screening tools designed to detect malnutrition risk generally focus on the following four determinants: body mass index/mid-arm circumference, recent weight loss, food intake and systemic diseases related to nutritional requirements [102]. In routine clinical settings, clinicians commonly use validated screening instruments such as the Mini Nutritional Assessment (MNA) [106], the Simplified Nutritional Appetite Questionnaire (SNAQ) [107], the Nutritional Risk Screening (NRS 2002) [108], the Seniors in the Community Risk Evaluation for Eating and Nutrition tool (SCREEN) [109], the Subjective Global Assessment (SGA) [110], and the Malnutrition Universal Screening Tool (MUST) [111].

The European Society of Clinical Nutrition and Metabolism (ESPEN) recommends the MNA [112], and the American Society for Parenteral and Enteral Nutrition (ASPEN) recommends the Subjective Global Assessment (SGA) [102]. The MNA is user friendly, easy to perform, applicable for both community dwelling and hospitalized elderly. A recent prospective cohort study in hospitalized elderly has shown that the MNA-Short Form (MNA-SF), NRS 2002, MUST, and SNAQ scales are reliable instruments for malnutrition risk assessment when compared to both the MNA and SGA [113].

The MUST [114] is a 5-step screening tool that estimates malnutrition risk in community-dwellers by assessing BMI, recent unintentional weight loss, and the occurrence of any acute disease affecting oral intake. It also includes management guidelines, whereas the NRS 2002 was developed for malnutrition assessment in hospital settings; it comprises the same nutritional components of the MUST, with an additional severity grading [102].

Table 3

Meals-on-wheels Mnemonic for reversible causes of weight loss

Medications (eg, digoxin, theophylline, cimetidine)

Emotional (eg, depression)

Alcoholism, elder abuse, anorexia tardive

Late life paranoia

Swallowing problems

Oral factors

Nosocomial infections (eg, tuberculosis)

Wandering and other dementia-related factors

Hyperthyroidism, Hypercalcemia, Hypoadrenalism

Enteral problems (eg, gluten enteropathy)

Eating problems

Low salt, low cholesterol, and other therapeutic diets

Stones (cholecystitis)

Morley JE. Weight Loss in the Nursing Home [104].
The MNA-SF was developed for malnutrition screening and assessment particularly in the elderly and is deemed to be valid across different settings including long-term care. It also explores physical and mental aspects affecting nutrition but does not consider severity of illness or current diagnosis. Using an MNA-SF score of $>$ or $=11$ as normal, excellent sensitivity, specificity and diagnostic accuracy for malnutrition were reported $(97.9 \%, 100 \%$, and $98.7 \%$ respectively) [115].

The SGA assesses nutritional status by relying on features from the medical history and physical examination, including the presence of cachexia and sarcopenia. However, the requirement of needing to be administered by a qualified professional, length of administration and lack of objective biological data such as laboratory findings and anthropometric measurements constitute limitations of this tool [4].

Despite the availability of numerous screening tools, none are deemed comprehensive. An optimal screening tool is characterized not only by high specificity and sensitivity but needs to be reliably used/ validated in different healthcare settings. It should also provide clear information about prognosis and grade/severity of malnutrition [4]. New screening tools incorporating body composition, inflammation, cognitive abilities in addition to sarcopenia and cachexia assessment are hence needed.

In addition to screening tools, physicians often rely on more objective anthropometric measurements such as the body mass index (BMI), the skin fold caliper, and biometric impedance analysis. However, these measures may yield unreliable findings in certain cases of change in posture, loss of muscle tone, ascites, or edema [116]. Specialized laboratory workup for malnutrition can be also ordered and includes transthyretin (pre-albumin), which has a three-day half-life. Useful labs to identify short term nutritional status may include albumin, ferritin, electrolytes, blood urea nitrogen, fasting glucose, C-reactive protein, and creatinine plasma levels [112].

\section{Treatment strategies}

Treatment approaches need to be tailored to the underlying etiology of the eating disturbances in older adults (dental problem, malignancy, hyperthyroidism, depression, etc.). However, even in the case of incurable diseases, such as MNCDs, different strategies can be used to improve patients' caloric intake and quality of life. 
Overall, providing adequate support from caretakers such as supervision during meals, emotional support, encouragement, and domestic help are shown to decrease the risk of low caloric intake [117]. Limiting strict restrictive diets often prescribed to patients suffering from cardiovascular diseases [118], in addition to adding taste enhancers (sauce) to regular food [119] may improve food pleasantness and promote weight gain.

In the case of insufficient caregiving and institutionalization, environmental control among elderly nursing home residents is effective in promoting appetite: changing the dining atmosphere to be more homelike by using tablecloths, napkins, easy-to-use silverware, frequent small meals, improved lighting, and use of relaxing music during meals $[120,121]$.

Using oral nutritional supplements (ONS) between meals is another way to increase daily caloric intake in the geriatric population, and particularly in patients with MNCDs. There is increasing evidence that ONS given in the liquid form do not induce satiety as much as the solid form, so it is unlikely that they would replace the main meal, and are thus effective in ensuring adequate daily caloric intake as well as improving rehabilitation outcomes [122-125]. A systematic review failed to show definitive evidence for or against any specific intervention for improving eating and drinking in cognitively impaired individuals, but based on small, short-term low-quality studies, ONS, food/drink modification (e.g. use of thickened liquids, finger foods, etc.), and providing mealtime assistance with staff/caretakers were shown to be promising interventions in this population [126].

If non-pharmacological approaches fail, appetitestimulating medication may be tried, and the choice of drug treatment is largely dependent on the patient profile and the etiology of appetite and weight loss [55].

In addition to its FDA approval for weight loss in patients with acquired immunodeficiency syndrome, megestrol acetate has been increasingly investigated for anorexia/cachexia in older adults and cancer patients. In a recent meta-analysis, it has been shown to be safe and well-tolerated and to significantly increase weight, but with no beneficial effect on quality of life or mortality rates $[127,128]$.

Synthetic tetrahydrocannabinol such as dronabinol and anabolic steroids like oxandrolone are other appetite stimulants that have shown to increase appetite and weight, especially against acquired immunodeficiency wasting syndrome $[129,130]$.
Mirtazapine is an antidepressant medication that also stimulates appetite. In a retrospective study with $\mathrm{AD}$ patients, $82 \%$ of patients attained significant weight gain after 6 months of use [131]. Mirtazapine has also shown promising results in a phase II clinical trial for treating cancer-related cachexia [132]. Although there is no data that directly investigates mirtazapine efficacy in depression-induced appetite loss, mirtazapine is the drug of choice in depressed patients with significant appetite and weight loss.

Weight gain is a well-known side effect of atypical antipsychotics: $80 \%$ of patients taking olanzapine, $50 \%$ of those taking quetiapine, and $58 \%$ of those on risperidone had significant weight gain of 7 pounds or more at week 52 [133]. Despite their beneficial effects on appetite and weight, antipsychotics are not typically used in the elderly to promote appetite, due to their increased risk of cerebrovascular events and the black box warning regarding increased mortality risk in patients with dementia [134].

\section{Conclusion}

Nutrition helps to promote health and quality of life, and nutritional well-being is one of the major determinants of successful aging. Eating disturbances are common in older adults and may lead to malnutrition, sarcopenia, frailty and worse health outcomes. In addition to age-related physiological changes, complex pathological and psychosocial factors may contribute to reduced food intake. Coexistence of systemic diseases, polypharmacy, functional decline, cognitive impairment and depressed mood are major contributors to malnutrition in the elderly. Although malnutrition is a common health problem, there is no universal agreement about its definition, assessment and diagnosis. Weight change is one of the simplest ways to predict nutritional status of individuals. Serial weight measurements can facilitate documentation of weight loss and alert physicians to perform further evaluation. Additionally, a number of screening tools can be used to identify high-risk individuals, among which the MNA-Short Form enables optimized, time saving assessment of nutritional status in the elderly, in various settings. It is thus recommended to screen all older adults for malnutrition and to intervene as early as possible, when necessary. Treatment strategies depend on the etiology underlying weight loss, but usually involve environmental changes and oral nutritional supplementations before 
pharmacotherapy. Moreover, patients should be followed over time and re-screened at regular intervals after development of advanced nutritional care plans in order to improve outcomes. Further studies are needed to develop a consensus definition for malnutrition and new comprehensive, reliable and userfriendly screening/diagnostic tools for malnutrition in older adults.

\section{Acknowledgments}

The authors have no acknowledgments.

\section{Funding}

The authors report no funding.

\section{Conflict of interest}

The authors have no conflict of interest to report.

\section{References}

[1] Profile of Older Americans 2016. Administration on Aging website. http://www.aoa.gov/AoARoot/Aging_Statistics/ Profile/index.aspx. Accessed March 29,2018.

[2] Sobotka L, editor. Basics in clinical nutrition. 4th ed. Galen; 2012.

[3] Morley JE. Undernutrition in older adults. Family Practice. 2012;29(Suppl 1):i89-i93.

[4] Jensen GL, Compher C, Sullivan DH, Mullin GE. Recognizing malnutrition in adults: Definitions and characteristics, screening, assessment, and team approach. JPEN Journal of Parenteral and Enteral Nutrition. 2013;37(6): 802-7.

[5] Bell CL, Tamura BK, Masaki KH, Amella EJ. Prevalence and measures of nutritional compromise among nursing home patients: Weight loss, low body mass index, malnutrition, and feeding dependency, a systematic review of the literature. Journal of the American Medical Directors Association. 2013;14(2):94-100.

[6] Thomas DR, Ashmen W, Morley JE, Evans WJ. Nutritional management in long-term care: Development of a clinical guideline. Council for Nutritional Strategies in Long-Term Care. The Journals of Gerontology Series A, Biological Sciences and Medical Sciences. 2000;55(12): M725-34

[7] Donini LM, Poggiogalle E, Molfino A, Rosano A, Lenzi A, Rossi Fanelli F, et al. Mini-nutritional assessment, malnutrition Universal screening tool, and nutrition risk screening tool for the nutritional evaluation of older nursing home residents. Journal of the American Medical Directors Association. 2016;17(10):959.e11-8.
[8] Agarwal E, Miller M, Yaxley A, Isenring E. Malnutrition in the elderly: A narrative review. Maturitas. 2013;76(4):296302.

[9] McDowell MA, Briefel RR, Alaimo K, Bischof AM, Caughman CR, Carroll MD, et al. Energy and macronutrient intakes of persons ages 2 months and over in the United States: Third National Health and Nutrition Examination Survey, Phase 1, 1988-91. Advance Data. 1994(255):1-24.

[10] Hallfrisch J, Muller D, Drinkwater D, Tobin J, Andres R. Continuing diet trends in men: The Baltimore Longitudinal Study of Aging (1961-1987). Journal of Gerontology. 1990;45(6):M186-91.

[11] Bernstein M. Nutritional needs of the older adult. Physical Medicine and Rehabilitation Clinics of North America. 2017;28(4):747-66.

[12] Cruz-Jentoft AJ, Kiesswetter E, Drey M, Sieber CC. Nutrition, frailty, and sarcopenia. Aging clinical and experimental research. 2017;29(1):43-8.

[13] Corkins MR, Guenter P, DiMaria-Ghalili RA, Jensen GL, Malone A, Miller S, et al. Malnutrition diagnoses in hospitalized patients: United States, 2010. JPEN Journal of Parenteral and Enteral Nutrition. 2014;38(2):186-95.

[14] Bernstein M, Munoz N. Position of the academy of nutrition and dietetics: Food and nutrition for older adults: Promoting health and wellness. Journal of the Academy of Nutrition and Dietetics. 2012;112(8):1255-77.

[15] Westenhoefer J. Age and gender dependent profile of food choice. Forum of Nutrition. 2005(57):44-51.

[16] Turner MD, Ship JA. Dry mouth and its effects on the oral health of elderly people. Journal of the American Dental Association (1939). 2007;138(Suppl):15s-20s.

[17] Gregersen H, Pedersen J, Drewes AM. Deterioration of muscle function in the human esophagus with age. Digestive Diseases and Sciences. 2008;53(12):3065-70.

[18] Gomez-Pinilla PJ, Gibbons SJ, Sarr MG, Kendrick ML, Shen KR, Cima RR, et al. Changes in interstitial cells of cajal with age in the human stomach and colon. Neurogastroenterology and Motility: The Official Journal of the European Gastrointestinal Motility Society. 2011;23(1): 36-44.

[19] Feldman M, Cryer B, McArthur KE, Huet BA, Lee E. Effects of aging and gastritis on gastric acid and pepsin secretion in humans: A prospective study. Gastroenterology. 1996;110(4):1043-52.

[20] Bhutto A, Morley JE. The clinical significance of gastrointestinal changes with aging. Current Opinion in Clinical Nutrition and Metabolic Care. 2008;11(5):651-60.

[21] Visvanathan R. Anorexia of aging. Clinics in Geriatric Medicine. 2015;31(3):417-27.

[22] Morley JE. Pathophysiology of the anorexia of aging. Current Opinion in Clinical Nutrition and Metabolic Care. 2013;16(1):27-32.

[23] Di Francesco V, Barazzoni R, Bissoli L, Fantin F, Rizzotti P, Residori L, et al. The quantity of meal fat influences the profile of postprandial hormones as well as hunger sensation in healthy elderly people. Journal of the American Medical Directors Association. 2010;11(3):188-93.

[24] Zamboni M,Zoico E, Fantin F, Panourgia MP, Di Francesco $\mathrm{V}$, Tosoni $\mathrm{P}$, et al. Relation between leptin and the metabolic syndrome in elderly women. The Journals of Gerontology Series A, Biological Sciences and Medical Sciences. 2004;59(4):396-400. 
[25] Rigamonti AE, Pincelli AI, Corra B, Viarengo R, Bonomo SM, Galimberti D, et al. Plasma ghrelin concentrations in elderly subjects: Comparison with anorexic and obese patients. The Journal of Endocrinology. 2002;175(1):R1-5.

[26] Chang GQ, Karatayev O, Ahsan R, Gaysinskaya V, Marwil Z, Leibowitz SF. Dietary fat stimulates endogenous enkephalin and dynorphin in the paraventricular nucleus: Role of circulating triglycerides. American Journal of Physiology Endocrinology and Metabolism. 2007;292(2):E561-70.

[27] Gruenewald DA, Marck BT, Matsumoto AM. Fastinginduced increases in food intake and neuropeptide $\mathrm{Y}$ gene expression are attenuated in aging male brown Norway rats. Endocrinology. 1996;137(10):4460-7.

[28] Morley JE. Developing novel therapeutic approaches to frailty. Current Pharmaceutical Design. 2009;15(29):338495.

[29] Woo J. Sarcopenia. Clinics in Geriatric Medicine. 2017; 33(3):305-14.

[30] Mitchell WK, Williams J, Atherton P, Larvin M, Lund J, Narici M. Sarcopenia, dynapenia, and the impact of advancing age on human skeletal muscle size and strength; a quantitative review. Frontiers in Physiology. 2012;3:260.

[31] Beaufrere B, Morio B. Fat and protein redistribution with aging: Metabolic considerations. European Journal of Clinical Nutrition. 2000;54(Suppl 3):S48-53.

[32] Rasmussen BB, Fujita S, Wolfe RR, Mittendorfer B, Roy $\mathrm{M}$, Rowe $\mathrm{VL}$, et al. Insulin resistance of muscle protein metabolism in aging. FASEB Journal: Official Publication of the Federation of American Societies for Experimental Biology. 2006;20(6):768-9.

[33] Bhasin S, Storer TW. Anabolic applications of androgens for functional limitations associated with aging and chronic illness. Frontiers of Hormone Research. 2009;37: 163-82.

[34] Geisler C, Braun W, Pourhassan M, Schweitzer L, Gluer CC, Bosy-Westphal A, et al. Age-dependent changes in resting energy expenditure (REE): Insights from detailed body composition analysis in normal and overweight healthy caucasians. Nutrients. 2016;8(6).

[35] Yeh SS, Blackwood K, Schuster MW. The cytokine basis of cachexia and its treatment: Are they ready for prime time? Journal of the American Medical Directors Association. 2008;9(4):219-36.

[36] Morley JE, Baumgartner RN. Cytokine-related aging process. The Journals of Gerontology Series A, Biological Sciences and Medical Sciences. 2004;59(9):M924-9.

[37] Raine KD. Improving nutritional health of the public through social change: Finding our roles in collective action. Canadian Journal of Dietetic Practice and Research: A Publication of Dietitians of Canada=Revue Canadienne de la Pratique et de la Recherche en Dietetique: Une Publication des Dietetistes du Canada. 2014;75(3):160-4.

[38] Wells JL, Dumbrell AC. Nutrition and aging: Assessment and treatment of compromised nutritional status in frail elderly patients. Clinical Interventions in Aging. 2006;1(1):67-79.

[39] Wysokinski A, Sobow T, Kloszewska I, Kostka T. Mechanisms of the anorexia of aging-a review. Age (Dordrecht, Netherlands). 2015;37(4):9821.

[40] Hsieh YM, Sung TS, Wan KS. A survey of nutrition and health status of solitary and non-solitary elders in taiwan.
The Journal of Nutrition, Health \& Aging. 2010;14(1): 11-4.

[41] Dong X, Simon MA. Association between reported elder abuse and rates of admission to skilled nursing facilities: Findings from a longitudinal population-based cohort study. Gerontology. 2013;59(5):464-72.

[42] Saarela RKT, Muurinen S, Suominen MH, Savikko NN, Soini H, Pitkala KH. Changes in malnutrition and quality of nutritional care among aged residents in all nursing homes and assisted living facilities in Helsinki 20032011. Archives of Gerontology and Geriatrics. 2017;72: 169-73.

[43] Soenen S, Chapman IM. Body weight, anorexia, and undernutrition in older people. Journal of the American Medical Directors Association. 2013;14(9):642-8.

[44] Bosch X, Monclus E, Escoda O, Guerra-Garcia M, Moreno $\mathrm{P}$, Guasch N, et al. Unintentional weight loss: Clinical characteristics and outcomes in a prospective cohort of 2677 patients. PloS One. 2017;12(4):e0175125.

[45] Galan Sanchez-Heredero MJ, Santander Vaquero C, Cortazar Saez M, de la Morena Lopez F, Susi Garcia R, Martinez Rincon Mdel C. Relationship between dysphagia and malnutritition in patients over 65 years of age. Enfermeria Clinica. 2014;24(3):183-90.

[46] Baijens LW, Clave P, Cras P, Ekberg O, Forster A, Kolb $\mathrm{GF}$, et al. European society for swallowing disorders european union geriatric medicine society white paper: Oropharyngeal dysphagia as a geriatric syndrome. Clinical Interventions in Aging. 2016;11:1403-28.

[47] Tomic S, Pekic V, Popijac Z, Pucic T, Petek M, Kuric $\mathrm{TG}$, et al. What increases the risk of malnutrition in Parkinson's disease? Journal of the Neurological Sciences. 2017;375:235-8.

[48] Visvanathan R, Newbury JW, Chapman I. Malnutrition in older people-screening and management strategies. Australian Family Physician. 2004;33(10):799-805.

[49] Bashashati M, Sarosiek I, McCallum RW. Epidemiology and mechanisms of gastroesophageal reflux disease in the elderly: A perspective. Annals of the New York Academy of Sciences. 2016;1380(1):230-4.

[50] Grassi M, Petraccia L, Mennuni G, Fontana M, Scarno A, Sabetta S, et al. Changes, functional disorders, and diseases in the gastrointestinal tract of elderly. Nutricion Hospitalaria. 2011;26(4):659-68.

[51] Madsen JL, Graff J. Effects of ageing on gastrointestinal motor function. Age and Ageing. 2004;33(2):154-9.

[52] Gidwaney NG, Bajpai M, Chokhavatia SS. Gastrointestinal Dysmotility in the Elderly. Journal of Clinical Gastroenterology. 2016;50(10):819-27.

[53] Favaro-Moreira NC, Krausch-Hofmann S, Matthys C, Vereecken C, Vanhauwaert E, Declercq A, et al. Risk factors for malnutrition in older adults: A systematic review of the literature based on longitudinal data. Advances in nutrition (Bethesda, Md). 2016;7(3):507-22.

[54] Syed Q, Hendler KT, Koncilja K. The impact of aging and medical status on dysgeusia. The American Journal of Medicine. 2016;129(7):753.e1-6.

[55] Viswambharan V, Manepalli JN, Grossberg GT. Orexigenic agents in geriatric clinical practice. Aging Health. 2013;9(1):49-65.

[56] Soysal P, Isik AT, Stubbs B, Solmi M, Volpe M, Luchini $\mathrm{C}$, et al. Acetylcholinesterase inhibitors are associated with 
weight loss in older people with dementia: A systematic review and meta-analysis. Journal of Neurology, Neurosurgery, and Psychiatry. 2016;87(12):1368-74.

[57] Grossberg G, Sadowsky C, Frostl H, Frolich L, Nagel $\mathrm{J}$, Tekin S, et al. Safety and tolerability of the rivastigmine patch: Results of a 28-week open-label extension. Alzheimer Disease and Associated Disorders. 2009;23(2):158-64.

[58] Cummings J, Lefevre G, Small G, Appel-Dingemanse S. Pharmacokinetic rationale for the rivastigmine patch. Neurology. 2007;69(4 Suppl 1):S10-3.

[59] Mangweth-Matzek B, Hoek HW, Pope HG, Jr. Pathological eating and body dissatisfaction in middle-aged and older women. Current Opinion in Psychiatry. 2014;27(6): 431-5.

[60] Lewis DM, Cachelin FM. Body image, body dissatisfaction, and eating attitudes in midlife and elderly women. Eating Disorders. 2001;9(1):29-39.

[61] Mangweth-Matzek B, Rupp CI, Hausmann A, Assmayr K, Mariacher E, Kemmler G, et al. Never too old for eating disorders or body dissatisfaction: A community study of elderly women. The International Journal of Eating Disorders. 2006;39(7):583-6.

[62] Conceicao EM, Gomes FVS, Vaz AR, Pinto-Bastos A, Machado PPP. Prevalence of eating disorders and picking/nibbling in elderly women. The International Journal of Eating Disorders. 2017;50(7):793-800.

[63] Luca A, Luca M, Calandra C. Eating disorders in late-life. Aging and Disease. 2015;6(1):48-55.

[64] Lapid MI, Prom MC, Burton MC, McAlpine DE, Sutor B, Rummans TA. Eating disorders in the elderly. International Psychogeriatrics. 2010;22(4):523-36.

[65] Elran-Barak R, Fitzsimmons-Craft EE, Benyamini Y, Crow SJ, Peterson CB, Hill LL, et al. Anorexia nervosa, bulimia nervosa, and binge eating disorder in midlife and beyond. The Journal of Nervous and Mental Disease. 2015;203(8):583-90.

[66] Ackard DM, Richter S, Egan A, Cronemeyer C. Poor outcome and death among youth, young adults, and midlife adults with eating disorders: An investigation of risk factors by age at assessment. The International Journal of Eating Disorders. 2014;47(7):825-35.

[67] Striegel-Moore RH, Garvin V, Dohm FA, Rosenheck RA. Eating disorders in a national sample of hospitalized female and male veterans: Detection rates and psychiatric comorbidity. The International Journal of Eating Disorders. 1999;25(4):405-14.

[68] Reas DL, Stedal K. Eating disorders in men aged midlife and beyond. Maturitas. 2015;81(2):248-55.

[69] American Psychiatric Association. Diagnostic and Statistical Manual of Mental Disorders. 5th ed. Washington, DC, 2013.

[70] Lowe B, Zipfel S, Buchholz C, Dupont Y, Reas DL, Herzog W. Long-term outcome of anorexia nervosa in a prospective 21-year follow-up study. Psychological Medicine. 2001;31(5):881-90.

[71] Cosford P, Arnold E. Eating disorders in later life: A review. International Journal of Geriatric Psychiatry. 1992;7(7):491-8.

[72] Hall P, Driscoll R. Anorexia in the elderly-an annotation. The International Journal of Eating Disorders. 1993;14(4):497-9.
[73] Beck D, Casper R, Andersen A. Truly late onset of eating disorders: A study of 11 cases averaging 60 years of age at presentation. The International Journal of Eating Disorders. 1996;20(4):389-95.

[74] Webster J, Tiggemann M. The relationship between women's body satisfaction and self-image across the life span: The role of cognitive control. The Journal of Genetic Psychology. 2003;164(2):241-52.

[75] Joughin NA, Crisp AH, Gowers SG, Bhat AV. The clinical features of late onset anorexia nervosa. Postgraduate Medical Journal. 1991;67(793):973-7.

[76] Nicholson SD, Ballance E. Anorexia nervosa in later life: An overview. Hospital Medicine (London, England: 1998). 1998;59(4):268-72.

[77] Russell J, Gilbert M. Is tardive anorexia a discrete diagnostic entity? The Australian and New Zealand Journal of Psychiatry. 1992;26(3):429-35.

[78] Cumella EJ, Kally Z. Comparison of middle-age and young women inpatients with eating disorders. Eating and Weight Disorders: EWD. 2008;13(4):183-90.

[79] Keel PK, Gravener JA, Joiner TE Jr, Haedt AA. Twentyyear follow-up of bulimia nervosa and related eating disorders not otherwise specified. The International Journal of Eating Disorders. 2010;43(6):492-7.

[80] Hudson JI, Hiripi E, Pope HG Jr, Kessler RC. The prevalence and correlates of eating disorders in the National Comorbidity Survey Replication. Biological Psychiatry. 2007;61(3):348-58.

[81] Friborg O, Martinussen M, Kaiser S, Overgard KT, Martinsen EW, Schmierer P, et al. Personality disorders in eating disorder not otherwise specified and binge eating disorder: A meta-analysis of comorbidity studies. The Journal of Nervous and Mental Disease. 2014;202(2): 119-25.

[82] Raevuori A, Suokas J, Haukka J, Gissler M, Linna M, Grainger M, et al. Highly increased risk of type 2 diabetes in patients with binge eating disorder and bulimia nervosa. The International Journal of Eating Disorders. 2015;48(6):555-62.

[83] Kaufer DI, Cummings JL, Ketchel P, Smith V, MacMillan A, Shelley T, et al. Validation of the NPI-Q, a brief clinical form of the Neuropsychiatric Inventory. The Journal of Neuropsychiatry and Clinical Neurosciences. 2000;12(2):233-9.

[84] Cipriani G, Carlesi C, Lucetti C, Danti S, Nuti A. Eating behaviors and dietary changes in patients with dementia. American Journal of Alzheimer's Disease and Other Dementias. 2016;31(8):706-16.

[85] Volkert D, Chourdakis M, Faxen-Irving G, Fruhwald T, Landi F, Suominen MH, et al. ESPEN guidelines on nutrition in dementia. Clinical Nutrition (Edinburgh, Scotland). 2015;34(6):1052-73.

[86] Sandilyan MB. Abnormal eating patterns in Dementia- a cause for concern. Age and Ageing. 2011; Volume 40(Issue eLetters Supplement).

[87] Ikeda M, Brown J, Holland AJ, Fukuhara R, Hodges JR. Changes in appetite, food preference, and eating habits in frontotemporal dementia and Alzheimer's disease. Journal of Neurology, Neurosurgery, and Psychiatry. 2002;73(4):371-6.

[88] Mendez MF, Licht EA, Shapira JS. Changes in dietary or eating behavior in frontotemporal dementia versus 
Alzheimer's disease. American Journal of Alzheimer's Disease and Other Dementias. 2008;23(3):280-5.

[89] Kai K, Hashimoto M, Amano K, Tanaka H, Fukuhara $\mathrm{R}$, Ikeda M. Relationship between eating disturbance and dementia severity in patients with Alzheimer's disease. PloS One. 2015;10(8):e0133666.

[90] Ahmed RM, Latheef S, Bartley L, Irish M, Halliday GM, Kiernan MC, et al. Eating behavior in frontotemporal dementia: Peripheral hormones vs hypothalamic pathology. Neurology. 2015;85(15):1310-7.

[91] Suh MK, Kim H, Na DL. Dysphagia in patients with dementia: Alzheimer versus vascular. Alzheimer Disease and Associated Disorders. 2009;23(2):178-84.

[92] Igoumenou A, Ebmeier KP. Diagnosing and managing vascular dementia. The Practitioner. 2012;256(1747):13-6, 2.

[93] Shinagawa S, Adachi H, Toyota Y, Mori T, Matsumoto I, Fukuhara R, et al. Characteristics of eating and swallowing problems in patients who have dementia with Lewy bodies. International Psychogeriatrics. 2009;21(3):520-5.

[94] Beekman AT, Copeland JR, Prince MJ. Review of community prevalence of depression in later life. The British Journal of Psychiatry: The Journal of Mental Science. 1999;174:307-11.

[95] Sozeri-Varma G. Depression in the elderly: Clinical features and risk factors. Aging and Disease. 2012;3(6): 465-71.

[96] Engel JH, Siewerdt F, Jackson R, Akobundu U, Wait C, Sahyoun N. Hardiness, depression, and emotional wellbeing and their association with appetite in older adults. Journal of the American Geriatrics Society. 2011;59(3): 482-7.

[97] Pilgrim AL, Robinson SM, Sayer AA, Roberts HC. An overview of appetite decline in older people. Nursing Older People. 2015;27(5):29-35.

[98] Tiemeier H. Biological risk factors for late life depression. European Journal of Epidemiology. 2003;18(8):745-50.

[99] Nho JH, Kim SR, Kwon YS. Depression and appetite: Predictors of malnutrition in gynecologic cancer. Supportive Care in Cancer: Official Journal of the Multinational Association of Supportive Care in Cancer. 2014;22(11): 3081-8.

[100] Britton B, Clover K, Bateman L, Odelli C, Wenham K, Zeman A, et al. Baseline depression predicts malnutrition in head and neck cancer patients undergoing radiotherapy. Supportive Care in Cancer: Official Journal of the Multinational Association of Supportive Care in Cancer. 2012;20(2):335-42.

[101] Potter GG, McQuoid DR, Steffens DC. Appetite loss and neurocognitive deficits in late-life depression. International Journal of Geriatric Psychiatry. 2015;30(6):647-54.

[102] Kondrup J, Allison SP, Elia M, Vellas B, Plauth M. ESPEN guidelines for nutrition screening 2002. Clinical Nutrition (Edinburgh, Scotland). 2003;22(4):415-21.

[103] Newman AB, Yanez D, Harris T, Duxbury A, Enright PL, Fried LP. Weight change in old age and its association with mortality. Journal of the American Geriatrics Society. 2001;49(10):1309-18.

[104] Morley JE. Weight loss in the nursing home. Journal of the American Medical Directors Association. 2007;8(4):201-4.

[105] White JV, Guenter P, Jensen G, Malone A, Schofield M. Consensus statement: Academy of Nutrition and Dietetics and American Society for Parenteral and Enteral Nutri- tion: Characteristics recommended for the identification and documentation of adult malnutrition (undernutrition). JPEN Journal of Parenteral and Enteral Nutrition. 2012;36(3):275-83.

[106] Guigoz Y. The Mini Nutritional Assessment (MNA) review of the literature-What does it tell us? The Journal of Nutrition, health \& Aging. 2006;10(6):466-85; discussion 85-7.

[107] Wilson MM, Thomas DR, Rubenstein LZ, Chibnall JT, Anderson S, Baxi A, et al. Appetite assessment: Simple appetite questionnaire predicts weight loss in community-dwelling adults and nursing home residents. The American Journal of Clinical Nutrition. 2005;82(5): 1074-81.

[108] Kondrup J, Rasmussen HH, Hamberg O, Stanga Z. Nutritional risk screening (NRS 2002): A new method based on an analysis of controlled clinical trials. Clinical Nutrition (Edinburgh, Scotland). 2003;22(3):321-36.

[109] Keller HH, McKenzie JD, Goy RE. Construct validation and test-retest reliability of the seniors in the community: Risk evaluation for eating and nutrition questionnaire. The Journals of Gerontology Series A, Biological Sciences and Medical Sciences. 2001;56(9):M552-8.

[110] Detsky AS, McLaughlin JR, Baker JP, Johnston N, Whittaker S, Mendelson RA, et al. What is subjective global assessment of nutritional status? JPEN Journal of Parenteral and Enteral Nutrition. 1987;11(1):8-13.

[111] Stratton RJ, Hackston A, Longmore D, Dixon R, Price S, Stroud M, et al. Malnutrition in hospital outpatients and inpatients: Prevalence, concurrent validity and ease of use of the 'malnutrition universal screening tool' ('MUST') for adults. The British Journal of Nutrition. 2004;92(5):799808.

[112] Cederholm T, Barazzoni R, Austin P, Ballmer P, Biolo G, Bischoff SC, et al. ESPEN guidelines on definitions and terminology of clinical nutrition. Clinical Nutrition (Edinburgh, Scotland). 2017;36(1):49-64.

[113] Young AM, Kidston S, Banks MD, Mudge AM, Isenring EA. Malnutrition screening tools: Comparison against two validated nutrition assessment methods in older medical inpatients. Nutrition (Burbank, Los Angeles County, Calif). 2013;29(1):101-6.

[114] Elia M. Screening for Malnutrition: A Multidisciplinary Responsibility. Development and Use of the Malnutrition Universal Screening Tool (MUST) for Adults. Malnutrition Advisory Group (MAG), a Standing Committee of BAPEN. Redditch, Worcs.: BAPEN; 2003.

[115] Rubenstein LZ, Harker JO, Salva A, Guigoz Y, Vellas B. Screening for undernutrition in geriatric practice: Developing the short-form mini-nutritional assessment (MNA-SF). The Journals of Gerontology Series A, Biological Sciences and Medical Sciences. 2001;56(6):M366-72.

[116] Ahmed T, Haboubi N. Assessment and management of nutrition in older people and its importance to health. Clinical Interventions in Aging. 2010;5:207-16.

[117] Nieuwenhuizen WF, Weenen H, Rigby P, Hetherington MM. Older adults and patients in need of nutritional support: Review of current treatment options and factors influencing nutritional intake. Clinical Nutrition (Edinburgh, Scotland). 2010;29(2):160-9.

[118] Locher JL, Goldsby TU, Goss AM, Kilgore ML, Gower B, Ard JD. Calorie restriction in overweight older adults: Do 
benefits exceed potential risks? Experimental Gerontology. 2016;86:4-13.

[119] Appleton KM. Increases in energy, protein and fat intake following the addition of sauce to an older person's meal. Appetite. 2009;52(1):161-5.

[120] Nijs KA, de Graaf C, Siebelink E, Blauw YH, Vanneste V, Kok FJ, et al. Effect of family-style meals on energy intake and risk of malnutrition in dutch nursing home residents: A randomized controlled trial. The Journals of Gerontology Series A, Biological Sciences and Medical Sciences. 2006;61(9):935-42.

[121] Nijs KA, de Graaf C, Kok FJ, van Staveren WA. Effect of family style mealtimes on quality of life, physical performance, and body weight of nursing home residents: Cluster randomised controlled trial. BMJ (Clinical Research ed). 2006;332(7551):1180-4.

[122] Allen V, Methven L, Gosney M. The influence of nutritional supplement drinks on providing adequate calorie and protein intake in older adults with dementia. The Journal of Nutrition, Health \& Aging. 2013;17(9):752-5.

[123] Niccoli S, Kolobov A, Bon T, Rafilovich S, Munro H, Tanner K, et al. Whey protein supplementation improves rehabilitation outcomes in hospitalized geriatric patients: A double blinded, randomized controlled trial. Journal of Nutrition in Gerontology and Geriatrics. 2017;36(4): 149-65.

[124] Cawood AL, Elia M, Stratton RJ. Systematic review and meta-analysis of the effects of high protein oral nutritional supplements. Ageing Research Reviews. 2012;11(2): 278-96.

[125] Leidy HJ, Apolzan JW, Mattes RD, Campbell WW. Food form and portion size affect postprandial appetite sensations and hormonal responses in healthy, nonobese, older adults. Obesity (Silver Spring, Md). 2010;18(2):293-9.

[126] Abdelhamid A, Bunn D, Copley M, Cowap V, Dickinson A, Gray L, et al. Effectiveness of interventions to directly support food and drink intake in people with dementia: Systematic review and meta-analysis. BMC Geriatrics. 2016;16:26.

[127] Greig CA, Johns N, Gray C, MacDonald A, Stephens NA, Skipworth RJ, et al. Phase I/II trial of formoterol fumarate combined with megestrol acetate in cachectic patients with advanced malignancy. Supportive Care in Cancer: Official Journal of the Multinational Association of Supportive Care in Cancer. 2014;22(5):1269-75.

[128] Ruiz Garcia V, Lopez-Briz E, Carbonell Sanchis R, Gonzalvez Perales JL, Bort-Marti S. Megestrol acetate for treatment of anorexia-cachexia syndrome. The Cochrane Database of Systematic Reviews. 2013(3):Cd004310.

[129] Badowski ME, Yanful PK. Dronabinol oral solution in the management of anorexia and weight loss in AIDS and cancer. Therapeutics and Clinical Risk Management. 2018;14:643-51.

[130] Berger JR, Pall L, Hall CD, Simpson DM, Berry PS, Dudley R. Oxandrolone in AIDS-wasting myopathy. AIDS (London, England). 1996;10(14):1657-62.

[131] Segers K, Surquin M. Can mirtazapine counteract the weight loss associated with Alzheimer disease? A retrospective open-label study. Alzheimer Disease and Associated Disorders. 2014;28(3):291-3.

[132] Riechelmann RP, Burman D, Tannock IF, Rodin G, Zimmermann C. Phase II trial of mirtazapine for cancer-related cachexia and anorexia. The American Journal of Hospice \& Palliative Care. 2010;27(2):106-10.

[133] McEvoy JP, Lieberman JA, Perkins DO, Hamer RM, Gu $\mathrm{H}$, Lazarus A, et al. Efficacy and tolerability of olanzapine, quetiapine, and risperidone in the treatment of early psychosis: A randomized, double-blind 52-week comparison. The American Journal of Psychiatry. 2007;164(7):1050-60.

[134] Kuehn BM. FDA warns antipsychotic drugs may be risky for elderly. Jama. 2005;293(20):2462. 